\title{
Stent Thrombosis: Incidence, Predictors and New Technologies
}

\author{
Gill Louise Buchanan, Sandeep Basavarajaiah, and Alaide Chieffo \\ Interventional Cardiology Unit, San Raffaele Scientific Institute, Via Olgettina 60, 20132 Milan, Italy \\ Correspondence should be addressed to Alaide Chieffo, chieffo.alaide@hsr.it
}

Received 1 November 2011; Accepted 20 December 2011

Academic Editor: Matthew J. Price

Copyright ( $) 2012$ Gill Louise Buchanan et al. This is an open access article distributed under the Creative Commons Attribution License, which permits unrestricted use, distribution, and reproduction in any medium, provided the original work is properly cited.

\begin{abstract}
Some concerns have been raised regarding the risk of late and very late stent thrombosis (ST) following drug-eluting stent implantation. Despite remaining an uncommon complication of percutaneous coronary intervention, when ST occurs, it can be catastrophic to the individual, commonly presenting as acute ST elevation myocardial infarction or sudden cardiac death. The incidence and predictors of ST have been reported in the literature and the role of dual antiplatelet therapies in the avoidance of such a complication remains vital. Ongoing studies are assessing the role of these therapies including platelet reactivity testing, genetic testing and optimum duration of therapy. In addition, newer polymer-free and bioabsorbable stents are under investigation in the quest to potentially minimise the risk of ST.
\end{abstract}

\section{Introduction}

Drug-eluting stents (DES) were introduced into clinical practice in order to reduce the rates of restenosis observed with bare metal stents (BMS) for the treatment of coronary artery disease [1-6]. However, despite the promising results, some concerns have been raised regarding the potential increased risk of late and very late stent thrombosis (ST) following DES implantation. This is felt to be a consequence of delayed endothelialization [7, 8]. The problem was first highlighted during the 2006 European Society of Cardiology and World Congress of Cardiology Meeting in Barcelona, Spain, when the results of two independent meta-analyses were presented demonstrating a higher mortality with DES [9]. This rapidly became known as the "ESC Firestorm," and, following this, an abundance of data from both randomized clinical trials and multicenter registries have suggested an increased risk of late and very late ST with the use of DES.

ST is a rare but usually catastrophic event, leading to acute vessel closure, frequently associated with ST elevation myocardial infarction (STEMI) or sudden cardiac death. This paper aims to review the current data regarding ST, the underlying causes and methods to reduce the risk. In addition, there is an emphasis on the importance of dual antiplatelet therapy (DAPT) and newer technologies under development, which may in time lead to a vast reduction in the incidence of ST.

\section{Definition of Stent Thrombosis according to the Academic Research Consortium}

In an attempt to standardize the definition of ST, the Academic Research Consortium (ARC) was formed in 2007, proposing the criteria illustrated in Table 1 [10]. Additionally, the timing of ST can be classified as acute $(<24$ hours post procedure), early ( 24 hours to 30 days post procedure), late (31 days to one year post procedure) and very late (>one year post procedure).

\section{Incidence of Stent Thrombosis}

The actual incidence of ST reported in the literature depends on the duration of follow-up utilized. During the early BMS era, ST was demonstrated to be as high as $20.0 \%$ [11]. Following this, advances in the field of interventional cardiology, including high pressure post dilatation and importantly, the addition of ticlopidine to aspirin, led to a significant decrease in the occurrence of ST $[12,13]$. It was observed that ST in BMS was uncommon after 30 days, due to complete endothelialization within this time [14], which was 
TABLE 1: ARC criteria for the diagnosis of stent thrombosis.

\begin{tabular}{ll}
\hline Definite & Angiographic or pathologic evidence of ST \\
\hline Probable & Unexplained death within 30 days of the procedure or \\
& MI at any time in the territory of previous PCI \\
Possible & Unexplained death occurring 30 days post procedure \\
\hline
\end{tabular}

ST: stent thrombosis; MI: myocardial infarction; PCI: percutaneous coronary intervention.

supported by a pooled analysis of a multicenter trial, when over $80.0 \%$ of angiographically confirmed ST occurred within the first 2 days of the procedure [15].

Similarly, most cases of ST occurring with DES occur within 30 days of the procedure. In the Dutch ST registry of over 21,000 patients who were treated with BMS and DES, the majority of ST cases $(>70.0 \%)$ were seen within the first month, with a cumulative incidence of definite ST of $2.1 \%$ over 3 years [16]. There were no differences demonstrated in the incidence of ST between BMS and DES. A further study by the Bern-Rotterdam group, which assessed 8,146 patients treated with DES (paclitaxel-eluting stents (PES) and sirolimus-eluting stents (SES)), reported a cumulative incidence of ST of $3.3 \%$ at 3 years. Moreover, the annual incidence of ST in this study was $0.5 \%$ [17]. Conversely, a study by a Japanese group (the J-Cypher registry) reported a lower incidence following SES implantation of definite ST at $0.8 \%$ over 2 years follow-up [18]. Furthermore, a comprehensive metaanalysis including 9,471 patients from 22 randomized trials, demonstrated no differences in overall mortality (Hazard Ratio (HR) 0.97; 95\% Confidence Interval (CI) 0.81-1.15; $P=0.72$ ) or myocardial infarction (MI) (HR 0.95; $95 \%$ CI $0.79-1.13 ; P=0.54)$ with DES compared with BMS. In the observational studies arm of this paper, amongst 182,901 patients in 34 studies, there were significant reductions in mortality (HR 0.78; 95\% CI 0.71-0.86) and MI (HR 0.87; 95\% CI 0.78-0.97) with DES [19]. A further meta-analysis of 13 randomized trials (7,352 patients) demonstrated that there was no increase in ST with DES (RR 0.97; 95\% CI 0.73$1.28)$ over 2 years [20].

Most of the earlier data in DES is obtained from the first generation DES, with the newer second generation DES thought to pose less risk. Studies evaluating their effectiveness over first generation DES have reported few cases of ST. Table 2 illustrates the incidence of ST in clinical trials of second generation DES. The trial "Clinical Evaluation of the Xience V Everolimus Eluting Coronary Stent System in the Treatment of Subjects with de Novo Coronary Artery Lesions" (SPIRIT IV), which evaluated the results of everolimus-eluting stents (EES) versus PES, reported ST in only $0.3 \%$ of EES patients in the first year compared with $0.8 \%$ of PES patients [21]. In the trial "A trial of EverolimusEluting Stents and Paclitaxel-Eluting Stents for Coronary Revascularization in Daily Practice" (COMPARE) which randomized 1,800 patients to EES or PES, the incidence of ST at one year was $1.0 \%$ following EES as compared with $3.0 \%$ in the PES group [22]. In addition, longer-term follow-up to 3 years showed no statistical difference in the occurrence of ST (EES 1.2\% versus SES 1.7\%) [23]. Similarly, the ENDEAVOR trials which evaluated the Zotarolimuseluting stent (ZES) reported a significantly lower incidence of ST compared to first generation DES [24-28]. Furthermore, the RESOLUTE all-comers trial showed the rate of ST was lower with EES compared with ZES $(0.3 \%$ versus $1.2 \%$; $P=0.01$ ) [29]. Additionally, a multicenter registry of 4,768 patients has been reported, which specifically assessed ST of second generation DES (EES and ZES). This demonstrated a cumulative incidence of definite ST in $1.0 \%$ of patients at 2 years follow-up. The incremental rate of ST from the first year to the second year was $0.25 \%$ [30]. Recently, data has shown no occurrence of very late ST at 3 years in 102 patients undergoing primary angioplasty for STEMI [31].

\section{Class Effect}

From the available data, it may be inferred that there is a class effect between the different drugs eluted from the permanent polymer stents. In a meta-analysis of 18,023 patients from randomized trials, there was an increased risk of definite late ST with PES versus SES (HR 1.85; 95\% CI 1.02-3.85; $P=$ 0.041) [7], which was also shown in other registry studies $[34,35]$. Conversely, the "Sirolimus Eluting Stent compared with Paclitaxel Eluting Stent for Coronary Revascularization" (SIRTAX) trial showed no difference between SES and PES (resp., $4.6 \%$ versus $4.1 \% ; P=0.74$ ) at 5 years follow-up [36]. Again, although ST is thought to be lower with the second generation "limus" family of drugs than PES [21, 22], no randomized studies have been adequately powered to assess ST; therefore, further data in this field is awaited.

\section{Prognosis Following Stent Thrombosis}

Many patients with ST present either as sudden cardiac death or as an acute STEMI. Those individuals who survive the initial event are known to have a poor prognosis [37]. It is important to emphasize that the case fatality rate in those individuals suffering a ST has been demonstrated to be as high as $45.0 \%$ in some series $[8,15,16,38-40]$. A study of 431 patients with angiographically confirmed definite ST demonstrated almost one in 5 patients with one definite ST experienced another ST at follow-up, showing the high-risk nature following the initial event [16].

Furthermore, a study of 985 patients who underwent primary angioplasty for STEMI, which included 102 patients with definite ST, demonstrated a higher occurrence of inhospital death or recurrent MI in those presenting with ST rather than STEMI secondary to a de novo lesion $(12.7 \%$ versus $7.4 \%$; $P=0.05$ ) [41]. However, of note, these patients had a higher proportion of comorbidities, including diabetes mellitus, chronic kidney disease and lower left ventricular ejection fraction which may have contributed to the difference in outcomes. Additionally, in those with STEMI secondary to ST, there was a larger thrombus burden, more frequent distal embolization and less successful results from PCI $[16,42]$. 
TABLE 2: Studies of second generation drug-eluting stents and the incidence of stent thrombosis.

\begin{tabular}{lccc}
\hline Study & Stent types & Followup (months) & Incidence of ST (\%) \\
\hline SORT OUT III [32] & ZES versus SES & 18 & 0.5 versus 1.0 \\
Resolute all-comers [29] & ZES versus EES & 12 & 1.2 versus 0.3 \\
ZEST [33] & ZES versus SES versus PES & 12 & 0.7 versus 0 versus 0.8 \\
ENDEAVOR IV [24] & ZES versus PES & 12 & 0.7 versus 0.1 \\
SPIRIT IV [21] & EES versus PES & 12 & 0.3 versus 0.8 \\
COMPARE [22] & EES versus PES & 12 & 1.0 versus 3.0 \\
\hline
\end{tabular}

SORT OUT III: Randomized Comparison of the Endeavor and the Cypher Coronary Stents in Non-Selected Angina Pectoris Patients; ZEST: Comparison of the Efficacy and the Safety of Zotarolimus-Eluting Stent Versus Sirolimus-Eluting Stent and PacliTaxel-Eluting Stent for Coronary Lesions; SPIRIT IV: Clinical Evaluation of the Xience V Everolimus Eluting Coronary Stent System in the Treatment of Subjects with de Novo Coronary Artery Lesions; COMPARE: A Trial of Everolimus-Eluting Stents and Paclitaxel-Eluting Stents for Coronary revascularization in Daily Practice; SES: Sirolimus-Eluting stent; PES: Paclitaxeleluting stent; ZES: Zotarolimus-eluting stent; EES: Everolimus-eluting stent.

\section{Predictors of Stent Thrombosis}

In general, ST occurs more frequently in complex patients with complex lesions, for example, acute coronary syndromes, diabetes mellitus, chronic kidney disease, small vessels and multiple stents, including bifurcation lesions and chronic total occlusion $[8,43,44]$. A summary of the underlying patient, lesion and procedural characteristics which are predictors of ST are illustrated in Table 3.

When a ST develops acutely, it is generally due to procedural-related factors, such as incomplete stent expansion, residual edge dissection, the presence of thrombus and reduced TIMI (Thrombolysis In Myocardial Infarction) flow grade $[8,16,17,45]$. Figure 1 demonstrates a case of acute ST which occurred in a patient following EES for a chronic total occlusion. The commonest reason for subacute and late $\mathrm{ST}$ is the discontinuation of DAPT, which will be discussed in more detail in a later section. Notably, risk factors for the development of very late ST are not so well defined. One possible explanation for such late occurrence is incomplete neointimal coverage as a result of delayed arterial healing, ongoing vessel wall inflammation and late acquired stent malapposition [46-50]. These phenomena have been observed in patients with DES by real-time imaging studies (angioscopy and optical coherence tomography (OCT)) [47, 49$51]$ and also in some autopsy studies of stented segments in patients with very late ST [46]. Figure 2 demonstrates a definite ST in a patient 18 months following SES implantation and evidence of thrombus on malapposed struts.

\section{Procedural Optimization}

In view of the clinical course associated with a ST, meticulous attention must be made to reduce the risk from the outset. Risk factors pertaining to the patients' history and lesion characteristics are non-modifiable; however, the procedure can be performed optimally to reduce the incidence of ST. Firstly, it is important to adequately screen the patient, to assess likely adherence to the necessary DAPT regimen, the bleeding risk and the need for any planned surgical procedures in the following 12 months.

The decision then needs to be made regarding the anticoagulation of choice during the procedure. However, this also carries risk, as bleeding complications may not be insignificant. Conventionally, unfractionated heparin has been the anticoagulant of choice in those undergoing PCI, often in combination with a glycoprotein IIb/IIIa inhibitor. In the "Controlled Abciximab and Device Investigation to Lower Late Angioplasty Complications" (CADILLAC) trial [52], abciximab use was an independent predictor of no ST (HR 0.27; 95\% CI 0.09-0.86; $P=0.026$ ). However, recently bivalirudin, a direct thrombin inhibitor, has become more widespread in use. In the "Harmonizing Outcomes with Revascularization and Stents in Acute Myocardial Infarction" (HORIZONS-AMI) trial which randomised 3,602 patients with STEMI undergoing primary angioplasty to heparin plus glycoprotein IIb/IIIa inhibitor versus bivalirudin monotherapy, acute ST occurred in patients assigned to bivalirudin more frequently $(1.4 \%$ versus $0.3 \%$; $P<0.001)$ with conversely ST after 24 hours occurring less frequently $(2.8 \%$ versus $4.4 \%, P=0.02$ ). Notably, there was no difference in the cumulative rates of ST at 2 years between the 2 groups (4.3\% versus $4.6 \% ; P=0.73)$ [53].

Furthermore, good lesion preparation (considering the use of rotational atherectomy in the presence of severely calcified lesions), use of properly sized stents and postdilatation with non compliant balloons, according to intravascular ultrasound (IVUS) guidance, may help adequate stent expansion and apposition. The space between the stent struts and vessel wall which is present when there is malapposition leads to an area of sluggish flow, which can allow thrombus formation. It is therefore essential to choose the correct stent size and perform effective high pressure postdilatation to reduce this risk. Adequate stent expansion on IVUS has been linked to lower ST at both 30 days and 12 months [54]. This can also ensure there are no remaining edge dissections which may be a nidus for ST.

Newer imaging modalities, such as OCT, may become a useful tool to help assessment of the substrates for ST development, thereby allowing optimization of the initial procedure. As discussed earlier, incomplete stent apposition may be associated with the formation of thrombus; on OCT, thrombus was seen significantly more frequently in struts that were not fully apposed compared to those with good apposition (20.6\% versus $2.0 \% ; P<0.001)$ [55]. Additionally, it has been shown that DES have a higher rate of uncovered and malapposed struts than BMS with OCT imaging [56]. 
TABle 3: Predictors of stent thrombosis.

\begin{tabular}{lll}
\hline Patient characteristics & Lesion characteristics & Procedural characteristics \\
\hline Diabetes mellitus & Long segment of disease & Stent underexpansion \\
Chronic kidney disease & Small diameter vessel & Stent malapposition \\
Acute presentation & Saphenous venous graft & Edge dissection \\
Current smoker & Chronic total occlusion & Strut fracture \\
Reduced left ventricular function & Bifurcation lesion & Multiple stent implantation and stent overlap \\
Cancer & & Geographic miss and residual stenosis \\
DAPT non-responsiveness & & Reduced TIMI flow alter procedure \\
Premature cessation of DAPT & & \\
Advanced age & & \\
Thrombocythemia & & \\
Hypersensitivity to polymer or drug &
\end{tabular}

DAPT: dual antiplatelet therapy; TIMI: thrombolysis in myocardial infarction.

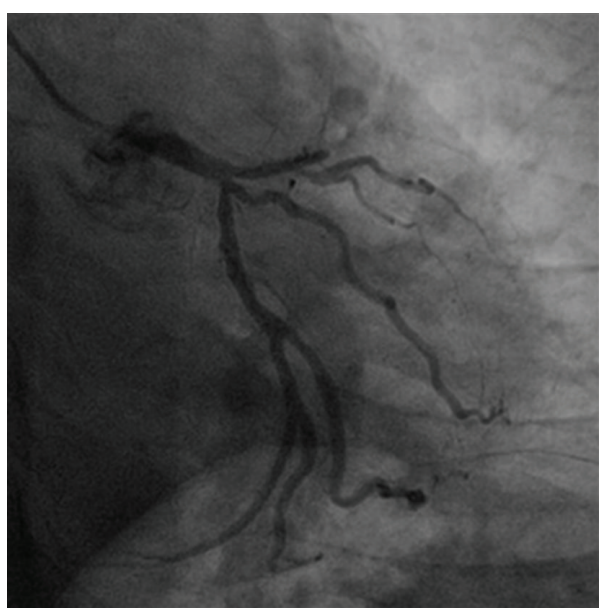

(a)

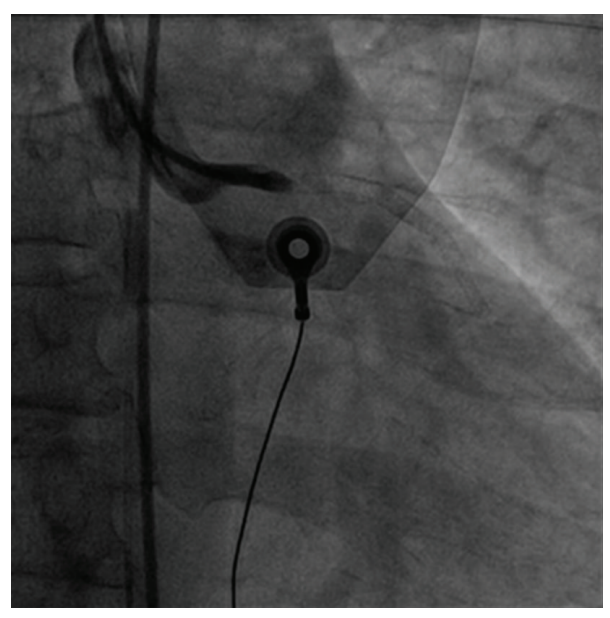

(c)

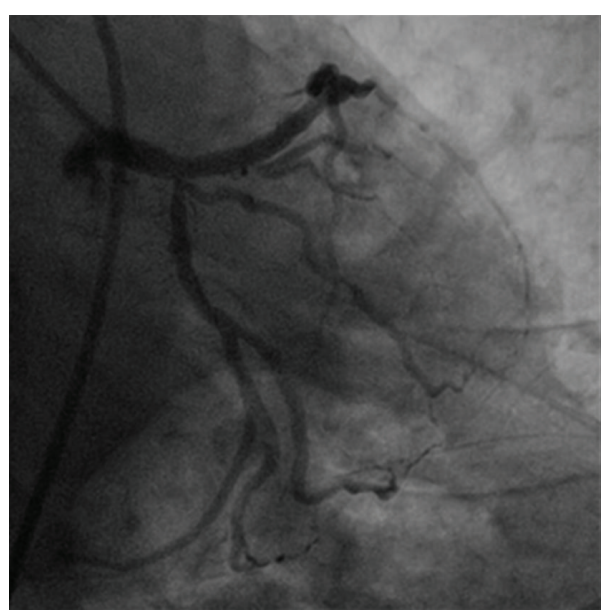

(b)

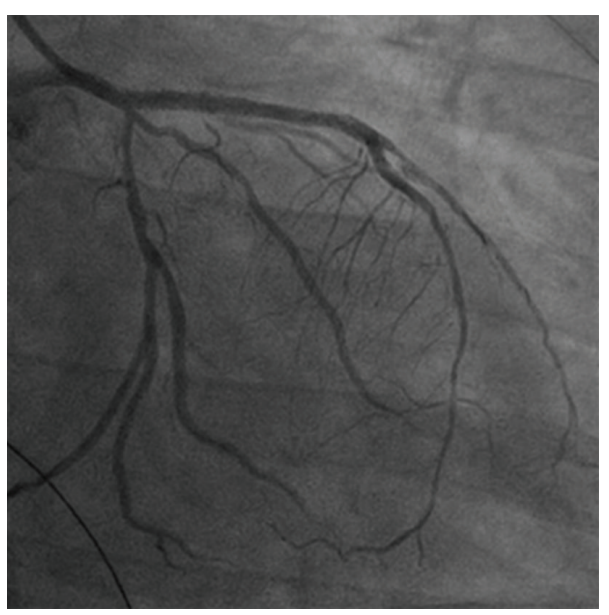

(d)

Figure 1: An illustration of how catastrophic stent thrombosis can be when it occurs. Panel (a) shows a chronic total occlusion of the left anterior descending coronary artery which was successfully opened (Panel (b)) with the implantation of everolimus-eluting stents (resp., $3.5 \times 33 \mathrm{~mm}$ and $2.75 \times 33 \mathrm{~mm}$ ). Twenty-four hours following the procedure, the patient became markedly hypotensive and symptomatic for angina, with EKG showing ST elevation in the anterior leads. Panel (c) demonstrates an acute stent thrombosis at the ostium of the vessel. Finally, Panel (d) shows the results following thrombus aspiration and plain optimal balloon angioplasty. 


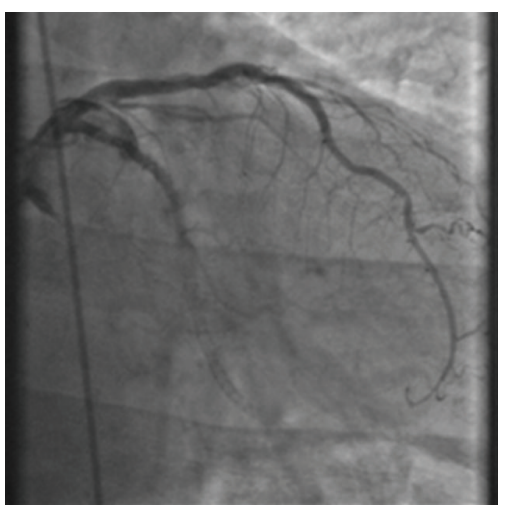

(a)

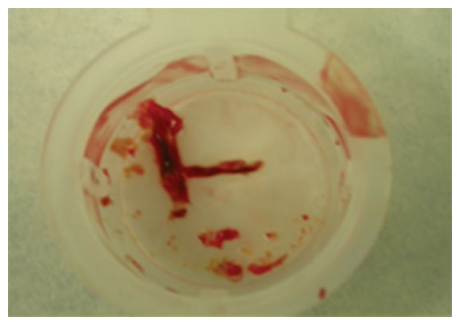

(b)

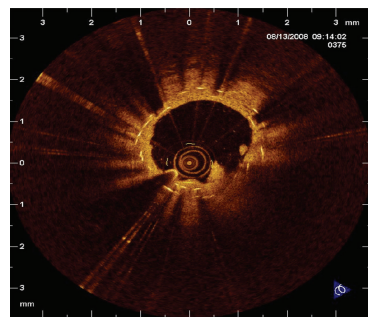

(c)

Figure 2: An illustration of a very late stent thrombosis 18 months following Sirolimus-eluting stent implantation in the circumflex artery. Panel (a) demonstrates the angiographic image. Panel (b) shows evidence of thrombus removed with a thrombus extraction system, and, finally Panel (c) illustrates malapposed struts and adherent thrombus following predilatation and assessment with optical coherence tomography.

\section{Correlation between Dual Antiplatelet Therapy and Stent Thrombosis}

The current recommendations from the American College of Cardiology/American Heart Association/Society for Cardiovascular Angiographic Intervention are that, following DES implantation, patients should receive clopidogrel (or an alternative thienopyridine) in addition to aspirin for a minimum of 12 months, unless there is a high bleeding risk or urgent circumstances arise [57]. The Task Force on myocardial revascularization of the European Society of Cardiology and the European Association for Cardiothoracic Surgery is less specific and state that convincing data exists only for continuation of DAPT up to 6 months [58].

However, the optimal duration after DES implantation remains unknown. The discontinuation of DAPT was the most powerful predictor of ST during the first 6 months following stent implantation in a cohort of over 3,000 patients (HR 13.74; 95\% CI 4.04-46.68; $P<0.001$ ) [59]. This was confirmed by a study by Schulz et al. in over 6,000 patients with 4-years follow up [60]. Furthermore, it has been demonstrated that ST occurred in $29.0 \%$ of patients who prematurely discontinued DAPT [8]. Conversely, the Bern/ Rotterdam registry of over 8,000 patients demonstrated no differences in those treated with clopidogrel for 12 months following DES implantation compared with those treated for only 3-6 months.

Alternatively, it has been suggested that patients treated with clopidogrel for 24 months had improved cumulative survival compared to those treated for 12 months [61]. However, it has been shown in a randomized trial of 2,701 patients who were free of major adverse cardiovascular and cerebrovascular events (MACCE) and major bleeding events for 12 months alter PCI receiving 12 versus 24 months of clopidogrel that the cumulative occurrence of definite ST at 24 months after DES was identical in patients who continued clopidogrel until 24 months $(0.4 \%$ versus $0.4 \% ; P=0.76)$ [62]. The "PROlonging Dual-antiplatelet treatment after Grading stent-Induced hyperplasia” [63] (PRODIGY) study was presented at the European Society of Cardiology Scientific Congress, Paris, 2011 which randomized 2,013 patients on an intention-to-stent basis to EES $(n=501)$, PES $(n=$ $505)$, ZES $(n=502)$, or BMS $(n=505)$. After 30 days, 1,970 were eligible for randomization to either 6 months DAPT $(n=983)$ or 24 months DAPT $(n=987)$ and followed up for 2 years. This showed no benefit of prolonged DAPT in the incidence of ischemic events at the cost of an increased risk of major bleeding (HR 2.17; 95\% CI 1.44-3.22; $P=0.00018$ ). The optimal duration is currently being assessed in a number of randomized trials illustrated in Table 4.

A number of factors have been thought to be implicated in the development of ST including clopidogrel resistance, hypersensitivity to the stent polymer, drug interactions and the discontinuation of clopidogrel within the first 6 months [59]. The measurement of platelet function on DAPT can enable those patients at highest risk to be identified [6668], as it is known individual responses to clopidogrel vary significantly [69]. One quarter of individuals may be resistant to the platelet-inhibiting effects of clopidogrel [70, 71]. A recent meta-analysis of over 3,000 patients demonstrated that high on treatment platelet reactivity tested by the VerifyNow assay (Accumetrics, San Diego, California, USA), defined as a P2YC12 Reaction Unit (PRU) of greater than or equal to 230, was associated with ST (HR 3.11; 95\% CI 1.506.46; $P=0.002$ ) [72]. Moreover, Parodi et al. demonstrated in 1,789 patients undergoing PCI who had platelet reactivity prospectively assessed using light transmittance aggregometry that a high residual platelet reactivity $(\geq 70 \%$ platelet aggregation) led to a higher incidence of ST (6.1\% versus $2.9 \% ; P=0.01)[73]$. However, even if we are aware of this, no benefit was shown in the "Gauging Responsiveness With a VerifyNow Assay: Impact on Thrombosis and Safety" (GRAVITAS) trial following double dose clopidogrel if there was high on treatment platelet reactivity [74]. In this study, the composite rate of cardiovascular death, MI, or ST was low in both groups $(2.3 \%)$ at 6 months. However, it is important to note that less than half of patients randomized to clopidogrel $150 \mathrm{mg}$ achieved appropriate variability in 
TABLE 4: Studies of ongoing randomized trials to assess optimal clopidogrel duration.

\begin{tabular}{|c|c|c|c|}
\hline Study & Patient population & Clopidogrel duration (months) & Primary endpoint \\
\hline $\begin{array}{l}\text { ISAR-SAFE } \\
{[64]}\end{array}$ & $\begin{array}{c}\text { Patients on clopidogrel } 6 \\
\text { months alter DES }\end{array}$ & 6 versus 12 & Composite of death, MI, ST, stroke and major bleeding \\
\hline DAPT [65] & All-comers & 12 versus 30 & Composite of death, MI, SI, stroke and major bleeding \\
\hline DAPT-STEMI & All STEMI patients & 6 versus 12 & MACCE \\
\hline SECURITY & Second-generation DES & 6 versus 12 & Definite/probable ST \\
\hline RESET & All-comers & 3 & Composite of cardiovascular death, MI, ST and major bleeding \\
\hline OPTIMIZE & $\begin{array}{l}\text { Stable CAD and } \\
\text { NSTEMI }\end{array}$ & 3 versus 12 & Composite of death, MI, stroke and major bleeding \\
\hline
\end{tabular}

ISAR-SAFE: Intracoronary Stenting and Antithrombotic Regimen: Safety and Efficacy of 6 Months Dual Antiplatelet Therapy After Drug-Eluting Stenting; DAPT: Dual Antiplatelet Therapy Study; STEMI: ST Elevation Myocardial Infarction; SECURITY: SECond generation drUg-eluting stents implantation followed by six-versus twelve-month dual antIplatElet therapy; RESET: A New Strategy Regarding Discontinuation of Dual Antiplatelets; OPTIMIZE: Optimized Duration of Clopidogrel Therapy Following Treatment with the Endeavor Zotarolimus Eluting Stent in the Real World Clinical Practice; DES: drug-eluting stent; CAD: coronary artery disease; NSTEMI: non-ST elevation myocardial infarction; MI: myocardial infarction; ST: stent thrombosis; MACCE: major adverse cardiovascular and cerebrovascular events.

antiplatelet response, which may have contributed to the lack of observed clinical effect. In addition, due to the lower than expected event rates, the study was underpowered to detect the clinical efficacy of high-dose clopidogrel. Another randomized study, "Testing Platelet Reactivity in Patients Undergoing Elective Stent Placement on Clopidogrel to Guide Alternative Therapy With Prasugrel" (TRIGGERPCI), comparing prasugrel to clopidogrel for those with high platelet reactivity was terminated early due to futility as high on clopidogrel platelet reactivity ( $>208$ PRU by VerifyNow) was observed less frequently than expected and there was a low occurrence of the primary endpoint of cardiac death or MI. There are a number of ongoing studies which aim to assess the utilization of platelet reactivity testing and optimization of DAPT following PCI, which are illustrated in Table 5.

Clopidogrel is a prodrug which requires conversion to an active metabolite to provide its effects and resistance can be due to a genetic variation in one of the cytochrome $\mathrm{P} 450$ hepatic enzymes necessary for this, particularly the CYP2C19 allele [75]. Patients with polymorphisms in this gene, which accounts for only $5-12 \%$ of clopidogrel response variability $[76,77]$, have more adverse clinical events following PCI. $[78,79]$. Indeed, this gene has been independently shown to be associated with early ST [80]. Despite this, currently genetic testing is not widely utilized in patients requiring stent implantation; however, the "Escalating Clopidogrel by Involving a Genetic Strategy-Thrombolysis In Myocardial Infarction 56" (ELEVATE-TIMI) study was recently reported [81]. The aim of this study was to assess whether higher doses of clopidogrel (up to $300 \mathrm{mg}$ ) improved responses in the setting of loss of function CYP2C19 genotypes. The genotypes of 333 patients with stable coronary artery disease were established, and it was shown that a dose of $225 \mathrm{mg}$ clopidogrel daily in CYP2C19 heterozygotes achieved levels of platelet reactivity similar to that seen with the standard $75 \mathrm{mg}$ dose in non-carriers. However, in homozygotes, doses of even $300 \mathrm{mg}$ did not result in comparable degrees of platelet inhibition. A number of studies are currently ongoing to further assess the role of CYP2C19 pharmacogenomics
(Table 6). Notably, the US Food and Drug Administration has added a box warning to clopidogrel about the reduced effectiveness in those patients who are poor metabolizers of the drug.

If a patient develops ST while fully compliant with DAPT, then consideration should be given to the modification of the drug regimen. Newer antiplatelet agents, including prasugrel [82] and ticagrelor [83], are now available which have been shown to be more potent, with a consequent reduction in ST $[84,85]$. Non responders to clopidogrel also respond well to these newer agents $[86,87]$. In patients with acute coronary syndromes, the rates of ST have been reduced by substituting clopidogrel with these drugs, at the risk of increased bleeding $[88,89]$. There is also the option of adding in therapy such as cilostazol, a phosphodiesterase inhibitor [90]. This has been shown in a registry study of 3,099 patients to reduce the risk of ST at 12 months as compared to DAPT only (HR 0.136; 95\% CI 0.035-0.521; $P=0.0036$ ) [91], with no increase in bleeding complications. However, most studies of cilostazol have been performed in Asians and have not been validated in the Western population.

Finally, drug interactions from other hepatic enzyme inhibitors can result in reduced effectiveness of clopidogrel. Importantly, in recent years, there has been concern regarding the use of concomitant proton pump inhibitors (PPIs) with clopidogrel [92]. However, the "Clopidogrel with or without omeprazole in coronary artery disease" (COGENT) trial which randomly assigned 3,873 patients on DAPT to omeprazole or placebo demonstrated no apparent cardiovascular interaction between the drugs [93]. However, this study was terminated early and therefore was underpowered for the endpoint. The American Heart Association guidelines do not prohibit the use of PPIs, yet highlight the potential risks and benefits of coadministering with clopidogrel [94]. Ongoing studies are assessing the role of CYP2C19 in the drug interaction between clopidogrel and PPIs: the "Evaluation of the Influence of Statins and Proton Pump Inhibitors on Clopidogrel Antiplatelet Effects" (SPICE) trial and the Influence of CYP2C19 Genetic Variants on Clopidogrel in Healthy Subjects Study. 
TABLE 5: A table to illustrate ongoing studies utilizing the results of platelet reactivity testing to assess outcomes following PCI.

\begin{tabular}{lccccc}
\hline Study & $\begin{array}{c}\text { Number of } \\
\text { patients }\end{array}$ & $\begin{array}{c}\text { Patient } \\
\text { population }\end{array}$ & $\begin{array}{c}\text { Platelet reactivity } \\
\text { value }\end{array}$ & Antiplatelet therapy & Primary endpoint \\
\hline ARCTIC & 2,500 & Elective PCI & $<15 \%$ & $\begin{array}{c}\text { GPIIb/IIIa inhibitors } \\
\text { Clopidogrel } 75 \text { mg versus } \\
\text { Clopidogrel } 150 \mathrm{mg}\end{array}$ & Death, MI, Stroke, TVR, ST \\
DANTE & 442 & NSTEMI & PRU $>240$ & Cardiovascular death, MI and TVR \\
\hline
\end{tabular}

ARCTIC: Monitored Adjusted Antiplatelet Treatment Versus a Common Antiplatelet Treatment for DES Implantation and Interruption Versus Continuation of Double Antiplatelet Therapy; DANTE: Dual Antiplatelet Therapy Tailored on the Extent of Platelet Inhibition; PCI: percutaneous coronary intervention; NSTEMI: Non-ST elevation myocardial infarction; GPIIb/IIIa: Glycoprotein IIb/IIIa inhibitor; MI: myocardial infarction; TVR: target vessel revascularization; ST: stent thrombosis; PRU: P2YC12 reaction unit.

TABLE 6: Ongoing studies assessing pharmacogenomics and antiplatelet therapy.

\begin{tabular}{|c|c|c|c|c|}
\hline Study & $\begin{array}{c}\text { Number of } \\
\text { patients }\end{array}$ & Patient population & Therapy & Primary endpoint \\
\hline GIFT & NA & $\begin{array}{l}\text { All-comers } \\
\text { undergoing PCI }\end{array}$ & $\begin{array}{l}\text { Tailored clopidogrel versus standard clopidogrel } \\
\text { according to platelet reactivity and genetic type }\end{array}$ & $\begin{array}{l}\text { Residual platelet ac- } \\
\text { tivity }\end{array}$ \\
\hline TARGET-PCI & 1,500 & Nonemergent PCI & $\begin{array}{l}\text { Tailored with clopidogrel and prasugrel to results } \\
\text { of platelet reactivity and genetic type }\end{array}$ & MACE \\
\hline CLOVIS-2 & 120 & Post-MI & $\begin{array}{l}\text { Clopidogrel } 300 \mathrm{mg} \text { versus Clopidogrel } 600 \mathrm{mg} \text { in } \\
22 \text { genetic CYP2C19 types }\end{array}$ & $\begin{array}{l}\text { Inhibition of resid- } \\
\text { ual platelet activity } \\
6 \text { hours following } \\
\text { clopidogrel }\end{array}$ \\
\hline PREDICT & 42 & Stable CAD & $\begin{array}{l}\text { Those with high residual platelet activity on } \\
\text { clopidogrel and genotyped for CYP2C19 treated } \\
\text { with double dose clopidogrel }\end{array}$ & $\begin{array}{l}\text { Change in residual } \\
\text { platelet activity }\end{array}$ \\
\hline GeCCO & 14,600 & Recent ACS & $\begin{array}{l}\text { Genotype-guided comparison of clopidogrel in } \\
\text { extensive metabolizers and prasugrel }\end{array}$ & $\begin{array}{l}\text { Cardiovascular } \\
\text { death, nonfatal MI, } \\
\text { or nonfatal stroke }\end{array}$ \\
\hline
\end{tabular}

GIFT: Genotype Information and Functional Testing; TARGET-PCI: Thrombocyte Activity Reassessment and Genotyping for PCI; CLOVIS-2: Clopidogrel and response Variability Investigation Study 2; PREDICT: Pilot Study on the Effect of High Clopidogrel Maintenance Dosing; GeCCO: Genotype Guided Comparison of Clopidogrel and Prasugrel Outcomes Study; PCI: percutaneous coronary intervention; MI: myocardial infarction; CAD: coronary artery disease; ACS: acute coronary syndrome; MACE: major adverse cardiovascular event.

\section{Impact of New Technologies}

Currently, there is much interest in the development of new technologies to improve safety outcomes, including a reduction in ST. It has been known for a number of years that durable polymers can cause local arterial injury [95]. Non erodible polymers provoke chronic eosinophilic infiltration within the arterial wall, suggestive of hypersensitivity reactions $[96,97]$. Concerns regarding the effects of these polymers had led to the design of stents with either biodegradable polymers or indeed no polymers, which are illustrated in Table 7.

The "Limus Eluted from A Durable versus ERodable Stent coating" (LEADERS) trial randomized 1,707 patients to either SES or biolimus A9-eluting stents (BES). The latter stent elutes biolimus from a polylactide biodegradable polymer applied to the abluminal surface of the stent which is fully metabolized within 6-9 months. At 3 years follow up, the rate of definite ST was $2.2 \%$ for the BES and $2.9 \%$ for the SES (HR 0.78; 95\% CI 0.43-1.43; $P=0.43$ ). However, interestingly, ST increased at a lower rate of $0.2 \%$ from one to 3 years for the BES compared with $0.9 \%$ for the SES. In addition, patients who had stopped DAPT did not appear to have any additional events at 3 years, with conversely in the SES group, there were development of events [98]. Furthermore, this may be explained by an OCT substudy of the LEADERS trial which demonstrated that BES had better strut coverage at 9 months than SES [99].

Further stents with biodegradable polymers are being developed and are showing promising results in early trials. The Biofreedom stent (Biosensors, Morges, Switzerland), which again is a BES, has demonstrated minimal delayed arterial healing [100]. Additionally, the Synergy stent (Boston Scientific, Natick, MA, USA) which has a bioabsorbable polymer and everolimus drug combination has recruited patients to the EVOLVE study (non-inferiority trial to assess the safety and performance of the evolution coronary stent), and the results are awaited. Finally, the CRE8 (CID, Saluggia, Italy) stent has recently gained CE mark. This is a unique polymer free abluminal reservoir technology together with a new amphilimus formulation which allows controlled and targeted drug elution to the artery. The results of the "International Randomized Comparison between DES Limus Carbostent and Taxus Drug Eluting Stents in the Treatment of De Novo Coronary Lesions" (NEXT) trial were presented at EuroPCR, Paris, France, in 2011 which demonstrated no ST at 180 days.

More recently, completely bioabsorbable stents have been developed to allow complete stent resorption, arterial healing 
TABLe 7: Newer stents.

\begin{tabular}{lcccl}
\hline Stent & Stent Platform & Polymer & Drug & Company \\
\hline Biomatrix & Stainless steel & PLA & Biolimus-A9 & Biosensors Inc., Newport Beach, CA, USA \\
JACTAX & Stainless steel & PLA & Paclitaxel & Boston Scientific, Natick, MA, USA \\
Nobori & Stainless steel & PLA & Biolimus-A9 & Termumo Medical Corp., Tokyo, Japan \\
Synergy & Platinum chromium & PLA & Everolimus & Boston Scientific, Natick, MA, USA \\
Janus Flex & Stainless steel & Carbofilm & Tacrolimus & Sorin, Italy \\
Biofreedom & Stainless steel & None & Biolimus-A9 & Biosensors Inc., Newport Beach, CA, USA \\
Cre8 & Cobalt chromium & None & Amphilimus & CID, Saluggia, Italy \\
Amazonia Pax & Cobalt chromium & None & Paclitaxel & Minvasys, Paris, France \\
VESTAsync & Stainless steel & None & Sirolimus & MIV Therapeutics, Atlanta, GA, USA \\
Yukon Choice & Stainless steel & None & Sirolimus & Translumina, Hechingen, Germany \\
\hline
\end{tabular}

PLA: polylactic acid.

and restoration of normal vascular function. As stent struts theoretically disappear, issues related to late persistent strut malapposition and chronically uncovered struts, including ST, become irrelevant. Additionally, there is elimination of chronic sources of vessel irritation and inflammation which could potentially reduce the need for prolonged DAPT. The "Clinical Evaluation of the Bioabsorbable Vascular Solutions Everolimus Eluting Coronary Stent System in the Treatment of Patients with Single De Novo Coronary Artery Lesions" (ABSORB) trial was a prospective multicenter, open-label, first-in-man study that assessed the bioabsorbable polymer stent in 30 patients. This has shown no cases of ST at 4 years follow up [101]. The results of the second cohort of the ABSORB trial with the second generation bioabsorbable stent have demonstrated no cardiovascular death at 12 months follow-up [102]. Currently, patients are being recruited for ABSORB Extend which aims to recruit 1,000 patients and follow up for the occurrence of ST. There are several bioabsorbable stents in development and in clinical trials. The REVA stent (REVA medical Inc., San Diego, CA, USA) coated with paclitaxel and the Bioabsorbable Therapeutics stent (Bioabsorbable Therapeutics Inc., Menlo Park, CA, USA) coated with sirolimus are currently being tested.

\section{Conclusions}

The occurrence of a ST is rare, however, remains one of the most feared complications following PCI, due to the potential catastrophic consequences. There are a number of factors that may lead to the development of a ST and it is essential that we optimize PCI technique and importantly DAPT regimens in all patients undergoing PCI. Newer stents are being developed at rapid rates, and future large-scale randomized trials may help in the decision making regarding these issues in an aim to reduce this dramatic event.

\section{Conflict of Interests}

None of the authors has any conflict of interests to disclose in relation to this paper.

\section{References}

[1] J. W. Moses, M. B. Leon, J. J. Popma et al., "Sirolimus-eluting stents versus standard stents in patients with stenosis in a native coronary artery," New England Journal of Medicine, vol. 349, no. 14, pp. 1315-1323, 2003.

[2] M. C. Morice, P. W. Serruys, J. E. Sousa et al., "A randomized comparison of a sirolimus-eluting stent with a standard stent for coronary revascularization," New England Journal of Medicine, vol. 346, no. 23, pp. 1773-1780, 2002.

[3] D. E. Cutlip, M. S. Chauhan, D. S. Baim et al., "Clinical restenosis after coronary stenting: perspectives from multicenter clinical trials," Journal of the American College of Cardiology, vol. 40, no. 12, pp. 2082-2089, 2002.

[4] C. Roiron, P. Sanchez, A. Bouzamondo, P. Lechat, and G. Montalescot, "Drug eluting stents: an updated meta-analysis of randomised controlled trials," Heart, vol. 92, no. 5, pp. 641-649, 2006.

[5] D. O. Williams, J. D. Abbott, and K. E. Kip, "Outcomes of 6906 patients undergoing percutaneous coronary intervention in the era of drug-eluting stents: report of the DEScover Registry," Circulation, vol. 114, no. 20, pp. 2154-2162, 2006.

[6] G. W. Stone, S. G. Ellis, L. Cannon et al., "Comparison of a polymer-based paclitaxel-eluting stent with a bare metal stent in patients with complex coronary artery disease: a randomized controlled trial," Journal of the American Medical Association, vol. 294, no. 10, pp. 1215-1223, 2005.

[7] C. Stettler, S. Wandel, S. Allemann et al., "Outcomes associated with drug-eluting and bare-metal stents: a collaborative network meta-analysis," Lancet, vol. 370, no. 9591, pp. 937948, 2007.

[8] I. Iakovou, T. Schmidt, E. Bonizzoni et al., "Incidence, predictors and outcome of thrombosis after succesful implantation of drug-eluting stents," Journal of the American Medical Association, vol. 293, no. 17, pp. 2126-2130, 2005.

[9] S. Cook and B. Meier, "Have we been misled by the ESC DES firestorm?” EuroIntervention, vol. 3, no. 5, pp. 535-537, 2008.

[10] D. E. Cutlip, S. Windecker, R. Mehran et al., "Clinical end points in coronary stent trials: a case for standardized definitions," Circulation, vol. 115, no. 17, pp. 2344-2351, 2007.

[11] P. W. Serruys, B. H. Strauss, K. J. Beatt et al., "Angiographic follow-up after placement of a self-expanding coronaryartery stent," New England Journal of Medicine, vol. 324, no. 1, pp. 13-17, 1991. 
[12] D. E. Cutlip, M. B. Leon, K. K. Ho et al., "Acute and ninemonth clinical outcomes after "suboptimal" coronary stenting: results from the STent Anti-thrombotic Regimen Study (STARS) registry," Journal of the American College of Cardiology, vol. 34, no. 3, pp. 698-706, 1999.

[13] A. Colombo, P. Hall, S. Nakamura et al., "Intracoronary stenting without anticoagulation accomplished with intravascular ultrasound guidance," Circulation, vol. 91, no. 6, pp. 1676-1688, 1995.

[14] M. Awata, J. Kotani, M. Uematsu et al., "Serial angioscopic evidence of incomplete neointimal coverage after sirolimuseluting stent implantation: comparison with bare-metal stents," Circulation, vol. 116, no. 8, pp. 910-916, 2007.

[15] D. E. Cutlip, D. S. Baim, K. K. Ho et al., "Stent thrombosis in the modern Era: a pooled analysis of multicenter coronary stent clinical trials," Circulation, vol. 103, no. 15, pp. 19671971, 2001.

[16] J. W. van Werkum, A. A. Heestermans, F. I. de Korte et al., "Long-term clinical outcome after a first angiographically confirmed coronary stent thrombosis: an analysis of 431 cases," Circulation, vol. 119, no. 6, pp. 828-834, 2009.

[17] P. Wenaweser, J. Daemen, M. Zwahlen et al., "Incidence and correlates of drug-eluting stent thrombosis in routine clinical practice. 4-year results from a large 2-institutional cohort study," Journal of the American College of Cardiology, vol. 52, no. 14, pp. 1134-1140, 2008.

[18] T. Kimura, T. Morimoto, Y. Nakagawa et al., "Antiplatelet therapy and stent thrombosis after sirolimus-eluting stent implantation," Circulation, vol. 119, no. 7, pp. 987-995, 2009.

[19] A. J. Kirtane, A. Gupta, S. Iyengar et al., "Safety and efficacy of drug-eluting and bare metal stents: comprehensive metaanalysis of randomized trials and observational studies," Circulation, vol. 119, no. 25, pp. 3198-3206, 2009.

[20] S. S. Brar, M. B. Leon, G. W. Stone et al., "Use of drug-eluting stents in acute myocardial infarction: a systematic review and meta-analysis," Journal of the American College of Cardiology, vol. 53, no. 18, pp. 1677-1689, 2009.

[21] G. W. Stone, A. Rizvi, K. Sudhir et al., "Randomized comparison of everolimus- and paclitaxel-eluting stents: 2year follow-up from the SPIRIT (clinical evaluation of the XIENCE $\mathrm{v}$ everolimus eluting coronary stent system) IV trial," Journal of the American College of Cardiology, vol. 58, no. 1, pp. 19-25, 2011.

[22] E. Kedhi, K. S. Joesoef, E. McFadden et al., "Second-generation everolimus-eluting and paclitaxel-eluting stents in reallife practice (COMPARE): a randomised trial," The Lancet, vol. 375, no. 9710, pp. 201-209, 2010.

[23] R. A. Byrne, A. Kastrati, S. Massberg et al., "Biodegradable polymer versus permanent polymer drug-eluting stents and everolimus- versus sirolimus-eluting stents in patients with coronary artery disease: 3 -year outcomes from a randomized clinical trial," Journal of the American College of Cardiology, vol. 58, no. 13, pp. 1325-1331, 2011.

[24] M. B. Leon, L. Mauri, J. J. Popma et al., "A randomized comparison of the ENDEAVOR zotarolimus-eluting stent versus the TAXUS paclitaxel-eluting stent in de novo native coronary lesions 12-month outcomes from the ENDEAVOR IV trial," Journal of the American College of Cardiology, vol. 55 , no. 6, pp. 543-554, 2010.

[25] I. T. Meredith, J. Ormiston, R. Whitbourn, I. P. Kay, D. Muller, and D. E. Cutlip, "Five-year clinical follow-up after implantation of the endeavor zotarolimus-eluting stent: ENDEAVOR I, first-in-human study," Catheterization and
Cardiovascular Interventions, vol. 74, no. 7, pp. 989-995, 2009.

[26] J. Fajadet, W. Wijns, G. J. Laarman et al., "Randomized, double-blind, multicenter study of the endeavor zotarolimus-eluting phosphorylcholine-encapsulated stent for treatment of native coronary artery lesions: clinical and angiographic results of the ENDEAVOR II trial," Circulation, vol. 114, no. 8, pp. 798-806, 2006.

[27] D. E. Kandzari, M. B. Leon, J. J. Popma et al., "Comparison of zotarolimus-eluting and sirolimus-eluting stents in patients with native coronary artery disease: a randomized controlled trial," Journal of the American College of Cardiology, vol. 48, no. 12, pp. 2440-2447, 2006.

[28] E. L. Eisenstein, M. B. Leon, D. E. Kandzari et al., "Long-term clinical and economic analysis of the Endeavor zotarolimuseluting stent versus the cypher sirolimus-eluting stent: 3year results from the ENDEAVOR III trial (Randomized Controlled Trial of the Medtronic Endeavor Drug [ABT-578] Eluting Coronary Stent System Versus the Cypher SirolimusEluting Coronary Stent System in De Novo Native Coronary Artery Lesions)," JACC: Cardiovascular Interventions, vol. 2, no. 12, pp. 1199-1207, 2009.

[29] S. Silber, S. Windecker, P. Vranckx, and P. W. Serruys, "Unrestricted randomised use of two new generation drugeluting coronary stents: 2-year patient-related versus stentrelated outcomes from the RESOLUTE All Comers trial," The Lancet, vol. 377, no. 9773, pp. 1241-1247, 2011.

[30] J. M. de la Torre Hernndez, F. Alfonso, F. Gimeno et al., "Thrombosis of second-generation drug-eluting stents in real practice: results from the multicenter Spanish registry ESTROFA-2 (estudio espaol sobre trombosis de stents farmacoactivos de segunda generacion-2)," JACC: Cardiovascular Interventions, vol. 3, no. 9, pp. 911-919, 2010.

[31] R. J. Shelton, K. Chitkara, R. Singh et al., "Three-year clinical outcome with the endeavor zotarolimus-eluting stent in primary percutaneous coronary intervention for st elevation myocardial infarction: the Endeavor Primary PCI Study (EPPCI)," Journal of Interventional Cardiology, vol. 24, no. 6, pp. 542-548, 2011.

[32] K. Rasmussen, M. Maeng, A. Kaltoft et al., "Efficacy and safety of zotarolimus-eluting and sirolimus-eluting coronary stents in routine clinical care (SORT OUT III): a randomised controlled superiority trial," The Lancet, vol. 375, no. 9720, pp. 1090-1099, 2010.

[33] D. W. Park, Y. H. Kim, S. C. Yun et al., "Comparison of zotarolimus-eluting stents with sirolimus- and paclitaxeleluting stents for coronary revascularization: the ZEST (comparison of the efficacy and safety of zotarolimus-eluting stent with sirolimus-eluting and paclitaxel-eluting stent for coronary lesions) randomized trial," Journal of the American College of Cardiology, vol. 56, no. 15, pp. 1187-1195, 2010.

[34] J. Daemen, P. Wenaweser, K. Tsuchida et al., "Early and late coronary stent thrombosis of sirolimus-eluting and paclitaxel-eluting stents in routine clinical practice: data from a large two-institutional cohort study," Lancet, vol. 369, no. 9562, pp. 667-678, 2007.

[35] A. Kaltoft, L. O. Jensen, M. Maeng et al., "2-year clinical outcomes after implantation of sirolimus-eluting, paclitaxeleluting, and bare-metal coronary stents: results from the WDHR (Western Denmark Heart Registry)," Journal of the American College of Cardiology, vol. 53, no. 8, pp. 658-664, 2009.

[36] L. Räber, L. Wohlwend, M. Wigger et al., "Five-year clinical and angiographic outcomes of a randomized comparison 
of sirolimus-eluting and paclitaxel-eluting stents: results of the sirolimus-eluting versus paclitaxel-eluting stents for coronary revascularization LATE trial," Circulation, vol. 123, no. 24, pp. 2819-2828, 2011.

[37] F. Burzotta, A. Parma, C. Pristipino et al., "Angiographic and clinical outcome of invasively managed patients with thrombosed coronary bare metal or drug-eluting stents: the OPTIMIST study," European Heart Journal, vol. 29, no. 24, pp. 3011-3021, 2008.

[38] P. K. Kuchulakanti, W. W. Chu, R. Torguson et al., "Correlates and long-term outcomes of angiographically proven stent thrombosis with sirolimus- and paclitaxel-eluting stents," Circulation, vol. 113, no. 8, pp. 1108-1113, 2006.

[39] T. Kimura, T. Morimoto, K. Kozuma et al., "Comparisons of baseline demographics, clinical presentation, and long-term outcome among patients with early, late, and very late stent thrombosis of sirolimus-eluting stents: observations from the registry of stent thrombosis for review and reevaluation (RESTART)," Circulation, vol. 122, no. 1, pp. 52-61, 2010.

[40] L. Mauri, W. H. Hsieh, J. M. Massaro, K. K. Ho, R. D'Agostino, and D. E. Cutlip, "Stent thrombosis in randomized clinical trials of drug-eluting stents," New England Journal of Medicine, vol. 356, no. 10, pp. 1020-1029, 2007.

[41] L. Belle, M. Mahmoudi, C. Delhaye et al., "Do patients with drug-eluting stent thrombosis have a similar prognosis to patients presenting with ST-Elevation myocardial infarction of de novo lesions?" Journal of Interventional Cardiology, vol. 24, no. 4, pp. 320-325, 2011.

[42] G. Sianos, M. I. Papafaklis, J. Daemen et al., "Angiographic stent thrombosis after routine use of drug-eluting stents in ST-segment elevation myocardial infarction: the importance of thrombus burden," Journal of the American College of Cardiology, vol. 50, no. 7, pp. 573-583, 2007.

[43] D. R. Holmes Jr., D. J. Kereiakes, S. Garg et al., "Stent thrombosis," Journal of the American College of Cardiology, vol. 56, no. 17, pp. 1357-1365, 2010.

[44] S. Windecker and B. Meier, "Late coronary stent thrombosis," Circulation, vol. 116, no. 17, pp. 1952-1965, 2007.

[45] E. Cheneau, L. Leborgne, G. S. Mintz et al., "Predictors of subacute stent thrombosis: results of a systematic intravascular ultrasound study," Circulation, vol. 108, no. 1, pp. 43-47, 2003.

[46] A. V. Finn, M. Joner, G. Nakazawa et al., "Pathological correlates of late drug-eluting stent thrombosis: strut coverage as a marker of endothelialization," Circulation, vol. 115, no. 18, pp. 2435-2441, 2007.

[47] M. Joner, A. V. Finn, A. Farb et al., "Pathology of drug-eluting stents in humans: delayed healing and late thrombotic risk," Journal of the American College of Cardiology, vol. 48, no. 1, pp. 193-202, 2006.

[48] D. Matsumoto, J. Shite, T. Shinke et al., "Neointimal coverage of sirolimus-eluting stents at 6-month follow-up: evaluated by optical coherence tomography," European Heart Journal, vol. 28, no. 8, pp. 961-967, 2007.

[49] S.-J. Kang, G. S. Mintz, T. Akasaka et al., "Optical coherence tomographic analysis of in-stent neoatherosclerosis after drug-eluting stent implantation," Circulation, vol. 123, no. 25, pp. 2954-2963, 2011.

[50] B. X. Chen, F. Y. Ma, W. Luo et al., "Neointimal coverage of bare-metal and sirolimus-eluting stents evaluated with optical coherence tomography," Heart, vol. 94, no. 5, pp. 566570, 2008.

[51] T. H. Kim, J. S. Kim, B. K. Kim et al., "Long-term (> / = 2) follow-up optical coherence tomographic study after sirolimus- and paclitaxel-eluting stent implantation: comparison to 9-month follow-up results," International Journal of Cardiovascular Imaging, vol. 27, no. 6, pp. 875-881, 2011.

[52] G. Dangas, E. D. Aymong, R. Mehran et al., "Predictors of and outcomes of early thrombosis following balloon angioplasty versus primary stenting in acute myocardial infarction and usefulness of abciximab (the CADILLAC trial)," American Journal of Cardiology, vol. 94, no. 8, pp. 983-988, 2004.

[53] G. D. Dangas, A. Caixeta, R. Mehran et al., "Frequency and predictors of stent thrombosis after percutaneous coronary intervention in acute myocardial infarction," Circulation, vol. 123, no. 16, pp. 1745-1756, 2011.

[54] P. Roy, D. H. Steinberg, S. J. Sushinsky et al., "The potential clinical utility of intravascular ultrasound guidance in patients undergoing percutaneous coronary intervention with drug-eluting stents," European Heart Journal, vol. 29, no. 15, pp. 1851-1857, 2008.

[55] Y. Ozaki, M. Okumura, T. F. Ismail et al., "The fate of incomplete stent apposition with drug-eluting stents: an optical coherence tomography-based natural history study," European Heart Journal, vol. 31, no. 12, pp. 1470-1476, 2010.

[56] G. Guagliumi, M. A. Costa, V. Sirbu et al., "Strut coverage and late malapposition with paclitaxel-eluting stents compared with bare metal stents in acute myocardial infarction: optical coherence tomography substudy of the harmonizing outcomes with revascularization and stents in acute myocardial infarction (HORIZONS-AMI) trial," Circulation, vol. 123, no. 3, pp. 274-281, 2011.

[57] S. B. King, S. C. Smith Jr., J. W. Hirshfeld Jr. et al., "2007 focused update of the ACC/AHA/SCAI 2005 guideline update for percutaneous coronary intervention: a report of the American College of Cardiology/American Heart Association task force on practice guidelines," Journal of the American College of Cardiology, vol. 51, no. 2, pp. 172-209, 2008.

[58] W. Wijns, P. Kolh, N. Danchin et al., "Guidelines on myocardial revascularization," European Heart Journal, vol. 31, no. 20, pp. 2501-2555, 2010.

[59] F. Airoldi, A. Colombo, N. Morici et al., "Incidence and predictors of drug-eluting stent thrombosis during and after discontinuation of thienopyridine treatment," Circulation, vol. 116, no. 7, pp. 745-754, 2007.

[60] S. Schulz, T. Schuster, J. Mehilli et al., "Stent thrombosis after drug-eluting stent implantation: incidence, timing, and relation to discontinuation of clopidogrel therapy over a 4-year period," European Heart Journal, vol. 30, no. 22, pp. 27142721, 2009.

[61] G. Tanzilli, C. Greco, F. Pelliccia et al., "Effectiveness of twoyear clopidogrel + aspirin in abolishing the risk of very late thrombosis after drug-eluting stent implantation (from the TYCOON [two-year ClOpidOgrel need] study)," American Journal of Cardiology, vol. 104, no. 10, pp. 1357-1361, 2009.

[62] S. J. Park, D. W. Park, Y. H. Kim et al., "Duration of dual antiplatelet therapy after implantation of drug-eluting stents," New England Journal of Medicine, vol. 362, no. 15, pp. 1374-1382, 2010.

[63] M. Valgimigli, G. Campo, G. Percoco et al., "Randomized comparison of 6-versus 24-month clopidogrel therapy after balancing anti-intimal hyperplasia stent potency in all-comer patients undergoing percutaneous coronary intervention: design and rationale for the PROlonging Dual-antiplatelet treatment after Grading stent-induced Intimal hyperplasia study (PRODIGY)," American Heart Journal, vol. 160, no. 5, pp. 804-811, 2010. 
[64] R. A. Byrne, S. Schulz, J. Mehilli et al., "Rationale and design of a randomized, double-blind, placebo-controlled trial of 6 versus 12 months clopidogrel therapy after implantation of a drug-eluting stent: the Intracoronary Stenting and Antithrombotic Regimen: safety and EFficacy of 6 Months Dual Antiplatelet Therapy after Drug-Eluting Stenting (ISARSAFE) study," American Heart Journal, vol. 157, no. 4, pp. 620-624.e2, 2009.

[65] L. Mauri, D. J. Kereiakes, S.-L. Normand et al., "Rationale and design of the dual antiplatelet therapy study, a prospective, multicenter, randomized, double-blind trial to assess the effectiveness and safety of 12 versus 30 months of dual antiplatelet therapy in subjects undergoing percutaneous coronary intervention with either drug-eluting stent or bare metal stent placement for the treatment of coronary artery lesions," American Heart Journal, vol. 160, no. 6, pp. 10351041.e1, 2010.

[66] A. M. Gori, R. Marcucci, A. Migliorini et al., "Incidence and clinical impact of dual nonresponsiveness to aspirin and clopidogrel in patients with drug-eluting stents," Journal of the American College of Cardiology, vol. 52, no. 9, pp. 734739, 2008.

[67] P. Barragan, J.-L. Bouvier, P.-O. Roquebert et al., "Resistance to thienopyridines: clinical detection of coronary stent thrombosis by monitoring of vasodilator-stimulated phosphoprotein phosphorylation," Catheterization and Cardiovascular Interventions, vol. 59, no. 3, pp. 295-302, 2003.

[68] P. Buonamici, R. Marcucci, A. Migliorini et al., "Impact of platelet reactivity after clopidogrel administration on drugeluting stent thrombosis," Journal of the American College of Cardiology, vol. 49, no. 24, pp. 2312-2317, 2007.

[69] D. J. Angiolillo, A. Fernandez-Ortiz, E. Bernardo et al., "Variability in individual responsiveness to clopidogrel: clinical implications, management, and future perspectives," Journal of the American College of Cardiology, vol. 49, no. 14, pp. 1505-1516, 2007.

[70] W. C. Lau, P. A. Gurbel, P. B. Watkins et al., "Contribution of hepatic cytochrome P450 3A4 metabolic activity to the phenomenon of clopidogrel resistance," Circulation, vol. 109, no. 2, pp. 166-171, 2004.

[71] P. A. Gurbel, K. P. Bliden, B. L. Hiatt, and C. M. O'Connor, "Clopidogrel for coronary stenting: response variability, drug resistance, and the effect of pretreatment platelet reactivity," Circulation, vol. 107, no. 23, pp. 2908-2913, 2003.

[72] S. S. Brar, J. Ten Berg, R. Marcucci et al., "Impact of platelet reactivity on clinical outcomes after percutaneous coronary intervention: a collaborative meta-analysis of individual participant data," Journal of the American College of Cardiology, vol. 58, no. 19, pp. 1945-1954, 2011.

[73] G. Parodi, R. Marcucci, R. Valenti et al., "High residual platelet reactivity after clopidogrel loading and long-term cardiovascular events among patients with acute coronary syndromes undergoing PCI," Journal of the American Medical Association, vol. 306, no. 11, pp. 1215-1223, 2011.

[74] M. J. Price, P. B. Berger, P. S. Teirstein et al., "Standardvs high-dose clopidogrel based on platelet function testing after percutaneous coronary intervention: the GRAVITAS randomized trial," Journal of the American Medical Association, vol. 305, no. 11, pp. 1097-1105, 2011.

[75] T. Simon, C. Verstuyft, M. Mary-Krause et al., "Genetic determinants of response to clopidogrel and cardiovascular events," New England Journal of Medicine, vol. 360, no. 4, pp. 363-375, 2009.
[76] A. R. Shuldiner, J. R. O'Connell, K. P. Bliden et al., "Association of cytochrome P450 2C19 genotype with the antiplatelet effect and clinical efficacy of clopidogrel therapy," Journal of the American Medical Association, vol. 302, no. 8, pp. 849857, 2009.

[77] W. Hochholzer, D. Trenk, M. F. Fromm et al., "Impact of cytochrome P450 2C19 loss-of-function polymorphism and of major demographic characteristics on residual platelet function after loading and maintenance treatment with clopidogrel in patients undergoing elective coronary stent placement," Journal of the American College of Cardiology, vol. 55, no. 22, pp. 2427-2434, 2010.

[78] D. R. Holmes Jr., G. J. Dehmer, S. Kaul, D. Leifer, P. T. O’Gara, and C. M. Stein, "ACCF/AHA clinical alert: ACCF/AHA clopidogrel clinical alert: approaches to the FDA "boxed warning" a report of the American college of cardiology foundation task force on clinical expert consensus documents and the American heart association," Circulation, vol. 122, no. 5, pp. 537-557, 2010.

[79] L. Bonello, U. S. Tantry, R. Marcucci et al., "Consensus and future directions on the definition of high on-treatment platelet reactivity to adenosine diphosphate," Journal of the American College of Cardiology, vol. 56, no. 12, pp. 919-933, 2010.

[80] G. Cayla, J.-S. Hulot, S. A. O’Connor et al., "Clinical, angiographic, and genetic factors associated with early coronary stent thrombosis," Journal of the American Medical Association, vol. 306, no. 16, pp. 1765-1774, 2011.

[81] J. L. Mega, W. Hochholzer, A. L. Frelinger III. et al., "Dosing clopidogrel based on CYP2C19 genotype and the effect on platelet reactivity in patients with stable cardiovascular disease," Journal of the American Medical Association, vol. 306, no. 20, pp. 2221-2228, 2011.

[82] L. Wallentin, C. Varenhorst, S. James et al., "Prasugrel achieves greater and faster P2Y12receptor-mediated platelet inhibition than clopidogrel due to more efficient generation of its active metabolite in aspirin-treated patients with coronary artery disease," European Heart Journal, vol. 29, no. 1, pp. 21-30, 2008.

[83] P. A. Gurbel, K. P. Bliden, K. Butler et al., "Randomized double-blind assessment of the ONSET and OFFSET of the antiplatelet effects of ticagrelor versus clopidogrel in patients with stable coronary artery disease: the ONSET/OFFSET study," Circulation, vol. 120, no. 25, pp. 2577-2585, 2009.

[84] S. D. Wiviott, E. Braunwald, D. J. Angiolillo et al., "Greater clinical benefit of more intensive oral antiplatelet therapy with prasugrel in patients with diabetes mellitus in the trial to assess improvement in therapeutic outcomes by optimizing platelet inhibition with prasugrel-thrombolysis in myocardial infarction 38," Circulation, vol. 118, no. 16, pp. 1626-1636, 2008.

[85] L. Wallentin, R. C. Becker, A. Budaj et al., "Ticagrelor versus clopidogrel in patients with acute coronary syndromes," New England Journal of Medicine, vol. 361, no. 11, pp. 1045-1057, 2009.

[86] S. D. Wiviott, D. Trenk, A. L. Frelinger et al., "Prasugrel compared with high loading- and maintenance-dose clopidogrel in patients with planned percutaneous coronary intervention: the prasugrel in comparison to clopidogrel for inhibition of platelet activation and aggregation-thrombolysis in myocardial infarction 44 trial," Circulation, vol. 116, no. 25, pp. 2923-2932, 2007.

[87] P. A. Gurbel, K. P. Bliden, K. Butler et al., "Response to ticagrelor in clopidogrel nonresponders and responders and 
effect of switching therapies: the RESPOND study," Circulation, vol. 121, no. 10, pp. 1188-1199, 2010.

[88] C. P. Cannon, R. A. Harrington, S. James et al., "Comparison of ticagrelor with clopidogrel in patients with a planned invasive strategy for acute coronary syndromes (PLATO): a randomised double-blind study," The Lancet, vol. 375, no. 9711, pp. 283-293, 2010.

[89] G. Montalescot, S. D. Wiviott, E. Braunwald et al., "Prasugrel compared with clopidogrel in patients undergoing percutaneous coronary intervention for ST-elevation myocardial infarction (TRITON-TIMI 38): double-blind, randomised controlled trial," The Lancet, vol. 373, no. 9665, pp. 723-731, 2009.

[90] Y. H. Jeong, S. W. Lee, B. R. Choi et al., "Randomized comparison of adjunctive cilostazol versus high maintenance dose clopidogrel in patients with high post-treatment platelet reactivity: results of the ACCEL-RESISTANCE (Adjunctive Cilostazol Versus High Maintenance Dose Clopidogrel in Patients With Clopidogrel Resistance) randomized study," Journal of the American College of Cardiology, vol. 53, no. 13, pp. 1101-1109, 2009.

[91] S. W. Lee, S. W. Park, S. C. Yun et al., "Triple antiplatelet therapy reduces ischemic events after drug-eluting stent implantation: drug-Eluting stenting followed by Cilostazol treatment REduces Adverse Serious cardiac Events (DECREASE registry)," American Heart Journal, vol. 159, no. 2, pp. 284 291.e1, 2010.

[92] M. L. O’Donoghue, E. Braunwald, E. M. Antman et al., "Pharmacodynamic effect and clinical efficacy of clopidogrel and prasugrel with or without a proton-pump inhibitor: an analysis of two randomised trials," The Lancet, vol. 374, no. 9694, pp. 989-997, 2009.

[93] D. L. Bhatt, B. L. Cryer, C. F. Contant et al., "Clopidogrel with or without omeprazole in coronary artery disease," New England Journal of Medicine, vol. 363, no. 20, pp. 1909-1917, 2010.

[94] R. S. Wright, J. L. Anderson, C. D. Adams et al., "2011 ACCF/AHA focused update of the Guidelines for the Management of Patients with Unstable Angina/Non-ST-Elevation Myocardial Infarction (updating the 2007 guideline): a report of the American College of Cardiology Foundation/American Heart Association Task Force on Practice Guidelines developed in collaboration with the American College of Emergency Physicians, Society for Cardiovascular," Journal of the American College of Cardiology, vol. 57, no. 19, pp. 1920-1959, 2011.

[95] W. J. Van der Giessen, A. M. Lincoff, R. S. Schwartz et al., "Marked inflammatory sequelae to implantation of biodegradable and nonbiodegradable polymers in porcine coronary arteries," Circulation, vol. 94, no. 7, pp. 1690-1697, 1996.

[96] G. Nakazawa, F. Otsuka, M. Nakano et al., "The pathology of neoatherosclerosis in human coronary implants: bare-metal and drug-eluting stents," Journal of the American College of Cardiology, vol. 57, no. 11, pp. 1314-1322, 2011.

[97] T. F. Lüscher, J. Steffel, F. R. Eberli et al., "Drug-eluting stent and coronary thrombosis: biological mechanisms and clinical implications," Circulation, vol. 115, no. 8, pp. 10511058, 2007.

[98] J. Wykrzykowska, P. Serruys, P. Buszman et al., "The three year follow-up of the randomised "all-comers" trial of a biodegradable polymer biolimus-eluting stent versus permanent polymer sirolimus-eluting stent (LEADERS)," EuroIntervention, vol. 7, no. 7, pp. 789-795, 2011.
[99] P. Barlis, E. Regar, P. W. Serruys et al., "An optical coherence tomography study of a biodegradable vs. durable polymercoated limus-eluting stent: a LEADERS trial sub-study," European Heart Journal, vol. 31, no. 2, pp. 165-176, 2010.

[100] N. Tada, R. Virmani, G. Grant et al., "Polymer-free Biolimus A9-coated stent demonstrates more sustained intimal inhibition, improved healing, and reduced inflammation compared with a polymer-coated sirolimus-eluting cypher stent in a porcine model," Circulation: Cardiovascular Interventions, vol. 3, no. 2, pp. 174-183, 2010.

[101] D. Dudek, Y. Onuma, J. A. Ormiston et al., "Four-year clinical follow-up of the ABSORB everolimus-eluting bioresorbable vascular scaffold in patients with denovo coronary artery disease: the ABSORB trial," EuroIntervention, vol. 7, no. 9, pp. 1060-1061, 2011.

[102] P. W. Serruys, Y. Onuma, D. Dudek et al., "Evaluation of the second generation of a bioresorbable everolimus-eluting vascular scaffold for the treatment of de Novo Coronary Artery stenosis: 12-month clinical and imaging outcomes," Journal of the American College of Cardiology, vol. 58, no. 15, pp. 1578-1588, 2011. 


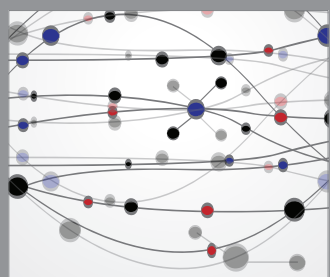

The Scientific World Journal
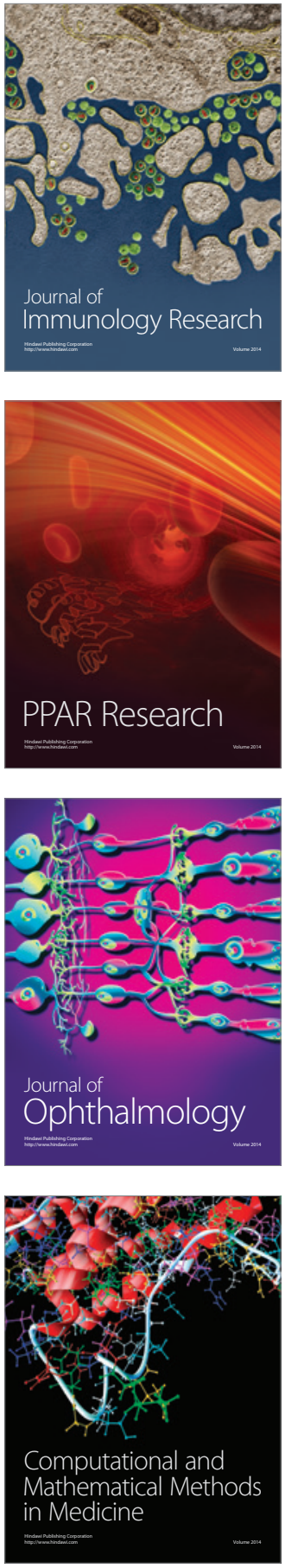

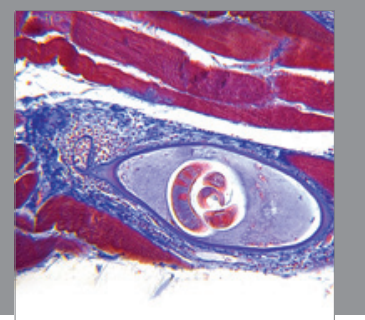

Gastroenterology

Research and Practice
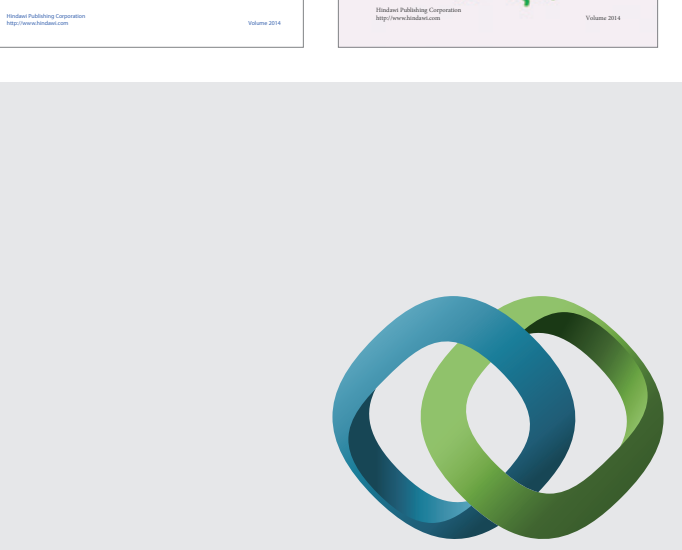

\section{Hindawi}

Submit your manuscripts at

http://www.hindawi.com
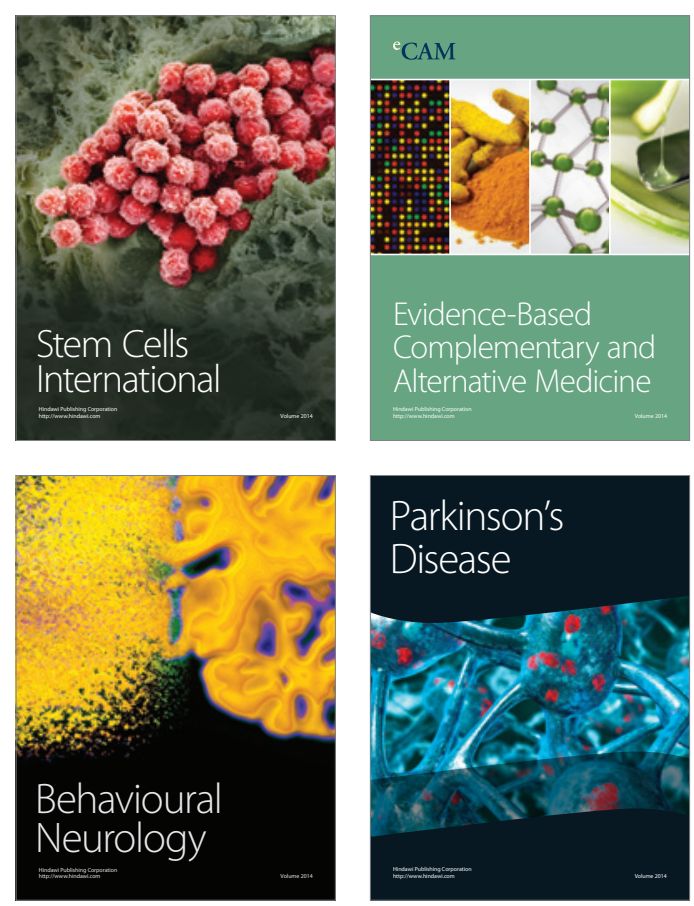

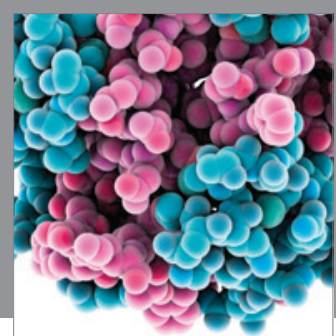

Journal of
Diabetes Research

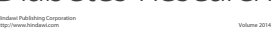

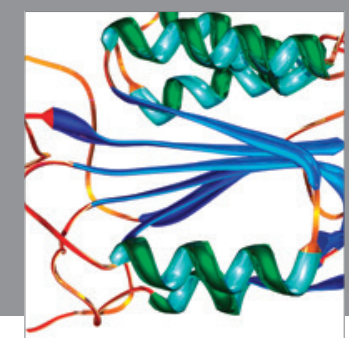

Disease Markers
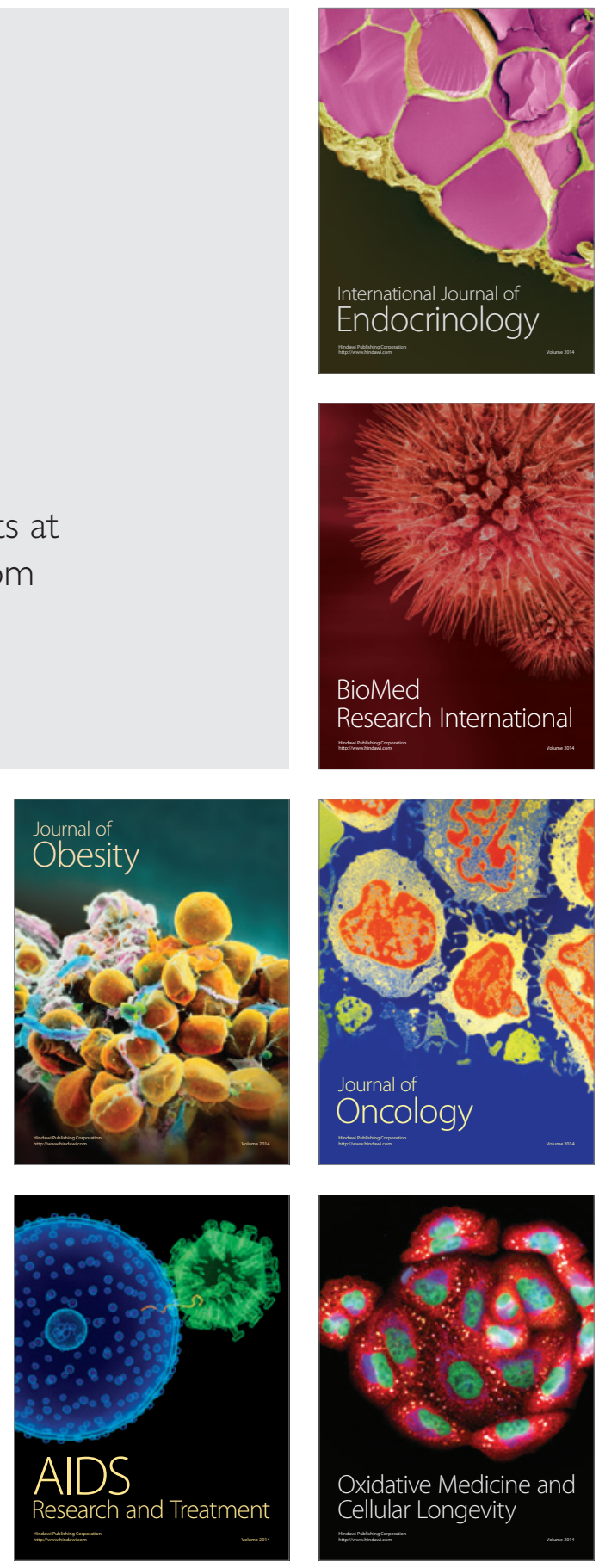